\title{
HOMO- AND HETERONUCLEAR COMPLEXES OF COPPER (II) WITH SCHIFF BASE OBTAINED ON THE BASE OF 2-HYDROXY-3-CARBOXYNAPHTALDEHYDE
}

\author{
A.G. Lazarescu *, T.C. Popa \\ Institute of Chemistry, Academy of Sciences of Republic Moldova, Academiei str.3, MD2028, Chisinau, Moldova \\ *lazarescu@mail.md, Phone: (3732)739722,Fax:(3732)739954
}

\begin{abstract}
The complexes of general formula $\mathrm{Cu}\left(\mathrm{H}_{2} \mathrm{~L}\right)$ (II); $\left[\mathrm{CuLn}(\mathrm{L})\left(\mathrm{NO}_{3}\right)\left(\mathrm{H}_{2} \mathrm{O}\right)_{\mathrm{n}}\right]$ (where $\mathrm{H}_{4} \mathrm{~L}=\mathrm{N}, \mathrm{N}^{\mathrm{I}}-$ bis $[2-$ hydroxy(3-carboxynaphtalidene)]ethylenediamine; $\mathrm{Ln}: \mathrm{Nd}, \mathrm{n}=6$ (III); $\mathrm{Eu}, \mathrm{n}=4$ (IV); Gd, $\mathrm{n}=6$ (V) have been synthesized and investigated by different methods (IR spectroscopy, TG analysis and magnetochemistry). The coordination set of complex generators are $\mathrm{Cu}\left(\mathrm{N}_{2} \mathrm{O}_{2}\right)$ and $\mathrm{Ln}\left(\mathrm{O}_{8-9}\right)$. The effective magnetic moment values, $\mu_{\text {eff, }}$ at $300 \mathrm{~K}$ are: 1.78 (II), 3.22 (III), 6.44 (V) B.M. The temperature dependence (300-2 K) of magnetic susceptibility of $\left[\mathrm{CuNd}(\mathrm{L})\left(\mathrm{NO}_{3}\right)\left(\mathrm{H}_{2} \mathrm{O}\right)_{6}\right]$ indicates the antiferromagnetic interaction between metal ions.
\end{abstract}

Keywords: copper (2+); d-f complexes; Schiff base; magnetic properties

\section{Introduction}

In the last time homo- and heteropolynuclear coordination compounds attract an increasing interest due to their unusual physicochemical properties caused by the character of a metal-metal exchange magnetic interaction [1-8]. One of the methods of synthesis of polynuclear compounds is the usage of polydentate ligands, which, using the donor atoms, have the ability to carry out stage coordination of two or several metal ions in dependence on their nature (d, f) and mutual arrangement in the molecules of these polydentate ligands [9-17]. The Schiff bases can serve an attractive example of such multifunctional ligands.

The purpose of the present investigation is the synthesis of new polidentate Schiff base to study an opportunity of stage synthesis of heteronuclear $(\mathrm{d}, \mathrm{f})$ coordination compounds and characterization of their physicochemical properties. In the present paper the results of synthesis and study of new azomethyne ligand $\left(\mathrm{H}_{4} \mathrm{~L}\right)(\mathbf{I})$ obtained by the condensation of 2-hydroxy-3-carboxynapthaldehyde [18] with ethylene diamine, and the complex compounds on its base are presented.<smiles>O=C(O)c1cc2ccccc2c(C=NCCN=Cc2c(O)c(C(=O)O)cc3ccccc23)c1O</smiles>

Also it is necessary to mention, that interest to this class of compounds is explained by its biological activity (antimicrobial, antitumor etc.) too [5, 19-21].

\section{Results and discussion}

Reaction of condensation of 2-hydroxy-3-carboxynapthaldehyde with ethylene diamine in the ratio 2:1 yielded a new polydentate Schiff base, N,N'-bis(2-hydroxy-3-carboxynaphtalidene)ethylenediamine $\left(\mathrm{H}_{4} \mathrm{~L}\right)$. The interaction of a synthesized ligand with the $\mathrm{Cu}^{2+}$ ions resulted the compound $\mathrm{CuH}_{2} \mathrm{~L}$ (II) of green color, which composition has been confirmed by the data of the elemental analysis.

The mode of ligand coordination in II was determined from the IR spectroscopy data. In the IR spectrum of $\mathrm{H}_{4} \mathrm{~L}$ the basic characteristic frequencies are presented at $3340,1707,1533 \mathrm{~cm}^{-1}$ and correspond to the stretching vibrations of hydroxy $v(\mathrm{OH})$, carboxy $v(\mathrm{COOH})$, and azomethine $(\mathrm{C}=\mathrm{N})$ groups [22]. They characterize the formation of the Schiff base. The comparison of the IR-spectra of the ligand and complex exhibits some essential differences: the stretching vibration band of azomethine fragment is shifted from 1533 to $1507 \mathrm{~cm}^{-1}$; the relative intensity of hydroxy band is decreased. At the same time the position of $v(\mathrm{CO})(\mathrm{COOH})$ band $\left(1707 \mathrm{~cm}^{-1}\right)$ practically doesn't change. These facts indicate the coordination of copper ion to oxygen of phenyl group and nitrogen of azomethine fragment with the formation of the more probable coordination set $\mathrm{CuO}_{2} \mathrm{~N}_{2}[17,22]$. The availability of non-coordinated carboxylic group in the synthesized $\mathrm{CuH}_{2} \mathrm{~L}$ compound affords a possibility of its use as a "ligand - complex" in the reaction with salts of homo- and heterometals.

By the reaction of $\mathrm{CuH}_{2} \mathrm{~L}$ compound with the lanthanide $(\mathrm{Nd}, \mathrm{Eu}, \mathrm{Sm})$ nitrate at the presence of $\mathrm{LiOH}$ results the heteronuclear coordination compounds of the composition $\left[\mathrm{CuLn}(\mathrm{L})\left(\mathrm{NO}_{3}\right)\left(\mathrm{H}_{2} \mathrm{O}\right) \mathrm{n}\right.$ ], where $\mathrm{Ln}$ : $\mathrm{Nd}, \mathrm{n}=6$ (III); Eu, $\mathrm{n}=4,(\mathbf{I V}) ; \mathrm{Sm}, \mathrm{n}=6(\mathbf{V})$.

In the IR spectra of copper - lanthanide complexes (III-V) the absorption band in the region $1707 \mathrm{~cm}^{-1}$ is absent and the new bands in the range of 3626-3380, 1620, 1400, and 1308-1312 $\mathrm{cm}^{-1}$ are presented. The absence of $1707 \mathrm{~cm}^{-1}$ absorption band indicates that the coordination of lanthanide ions to the deprotonated of carboxylic groups is realized. The absorption bands in the field of 1620 and $1400 \mathrm{~cm}^{-1}$ are characteristic for asymmetric and symmetric vibrations of carboxylic group, $v_{\mathrm{as}, \mathrm{s}}(\mathrm{COO})$. The occurrence of a broad absorption band in the range $3626-3380 \mathrm{~cm}^{-1}$, typical for $v_{\text {ass, }}(\mathrm{OH})$, confirms the presence of water molecules in the composition of heterometallic complexes, which complete the coordination number of lanthanide ions up to 8-9. 
Table 1.

Data of the thermal analysis of the complexes with composition [CuLn(L)(NO $\left.\left.\mathrm{N}_{3}\right)\left(\mathrm{H}_{2} \mathrm{O}\right) n\right]$, where Ln: Nd, n=6 (III), Eu, n=4 (IV);Gd, n= 6 (V).

\begin{tabular}{|c|c|c|c|c|c|c|}
\hline \multirow[t]{2}{*}{ Compound } & \multirow{2}{*}{$\begin{array}{c}\text { Number } \\
\text { of } \\
\text { effects }\end{array}$} & \multirow[t]{2}{*}{ Effect } & \multicolumn{3}{|c|}{$\begin{array}{c}\text { Temperature of } \\
\text { decomposition, }{ }^{\circ} \mathrm{C}\end{array}$} & \multirow[t]{2}{*}{$\begin{array}{l}\text { Loss of mass, } \\
\% ; \text { (corresponds) }\end{array}$} \\
\hline & & & $T_{\text {init }}$ & $\mathrm{T}_{\max }$ & $T_{\text {fin }}$ & \\
\hline \multirow[t]{3}{*}{ III } & 1 & endo & 20 & 80 & 180 & $13(13) \quad\left(-6 \mathrm{H}_{2} \mathrm{O}\right)$ \\
\hline & 2 & exo & 180 & & 340 & $23(36)$ \\
\hline & 3 & exo & 340 & & 640 & $38(74)$ \\
\hline \multirow[t]{3}{*}{ IV } & 1 & endo & 20 & 70 & 140 & $8(8) \quad\left(-4 \mathrm{H}_{2} \mathrm{O}\right)$ \\
\hline & 2 & exo & 140 & 190 & 320 & $25(33)$ \\
\hline & 3 & exo & 320 & - & 570 & $44(77)$ \\
\hline \multirow[t]{3}{*}{ V } & 1 & endo & 25 & 70 & 170 & $11(11)\left(5-6 \mathrm{H}_{2} \mathrm{O}\right)$ \\
\hline & 2 & exo & 170 & 290 & 330 & $26(33)$ \\
\hline & 3 & exo & 330 & - & 590 & $45(78)$ \\
\hline
\end{tabular}

The data of the element analysis for compounds III-V specify the availability of no more than one nitrategroup in the complexes necessary for the neutralization of a charge $(+3)$ of a lanthanide ion. According to the literary data $[10,22]$, bidentate nitrate-group is usually characterized by four absorption bands: 1450-1500, 1300, 1030, and $815 \mathrm{~cm}^{-1}$. Due to the overlap of different bands in the IR spectra of copper-lanthanide compounds in this region, only one new band was found in the range $1308-1312 \mathrm{~cm}^{-1}$, which was assigned to the coordination of nitrate anion, entering in the inner coordination sphere of the complex. This effect probably explains the low solubility of these compounds. The observed identity of the IR spectra of heterocomplexes III-V specifies their isostructural character.

The thermal stability of the heteronuclear compounds III-V was determined by TGA method. The derivatograms of heterocomplexes have the similar shape that testifies the analogy in a composition and structure of the studied compounds (III-V). The thermal decomposition of investigated compounds proceeds in several stages (tab. 1). In the temperature region of $20-180^{\circ} \mathrm{C}$ for all the compounds the endothermic effect is observed, which corresponds to the loss of crystallization as well as coordinated water molecules. In the $180-640{ }^{\circ} \mathrm{C}$ temperature region two exothermic effects are observed, which correspond to the gradual combustion of the ligand and complete decomposition of the complexes. The decomposition

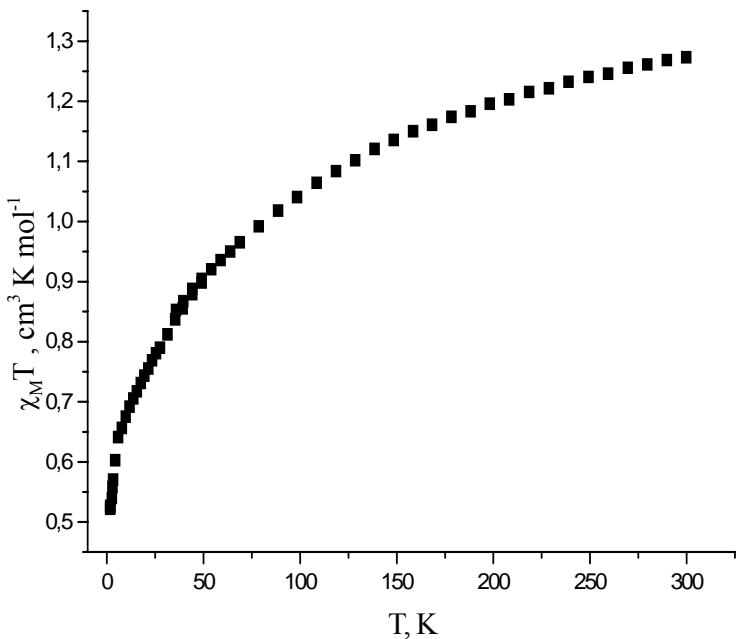

Figure 1.Dependence $\chi_{M} T(T)$ for compound $\left[\mathrm{Cu}(\mathrm{L}) \mathrm{Nd}\left(\mathrm{H}_{2} \mathrm{O}\right)_{6}\right]\left(\mathrm{NO}_{3}\right)$ residues in the form of mixed oxides constitute $25-29 \%$ of the full mass. The data of the thermogravimetric analysis are in according to the elemental analysis data.

Magnetic susceptibility studies. Room and variabletemperature of magnetic succeptibility $\left(\chi_{m}\right)$ study have been performed on powdered samples of synthesized (II, III,V) complexes. The effective magnetic moment $\mu_{3 \phi}$ of II at room temperature is found to be equal to 1.78 M.B. i.e. the monomeric structure of complex is realized. The values of effective magnetic moments for heterocomplexes III, $\mathbf{V}(\mathrm{T}=300 \mathrm{~K})$ are equal to 3.31 and 6.64 M.B., respectively, and specify the availability of lanthanide ions in the structure of these complexes [2]. Temperature dependence of the magnetic susceptibility of $\left\{\mathrm{Cu}(\mathrm{L}) \mathrm{Nd}\left(\mathrm{H}_{2} \mathrm{O}\right)_{6}\left(\mathrm{NO}_{3}\right)\right\}$, is shown in fig. 1. At $300 \mathrm{~K}$ the $\chi_{\mathrm{M}} \mathrm{T}$ is equal $1.273 \mathrm{~cm}^{3} \cdot \mathrm{K} \cdot \mathrm{mol}{ }^{-1}$. With decrease of temperature the $\chi_{\mathrm{M}} \mathrm{T}$ value is diminished up to 0.527 $\mathrm{cm}^{3} \cdot \mathrm{K} \cdot \mathrm{mol}^{-1}$ at $1.7 \mathrm{~K}$, that indicates the predominant antiferromagnetic interaction between the copper(II) and neodymium(III) ions.

In conclusion, the synthesized ligand forms the

homonuclear copper(2+) compounds, which can be used as ligand for synthesis of new heteronuclear complexes with $\mathrm{f}$ or d-elements. In the synthesized heterocomplexes the copper (II) and lanthanide (III) ions are bound at the inside $\left(\mathrm{N}_{2} \mathrm{O}_{2}\right)$ and the outside $\left(\mathrm{O}_{4}\right)$ coordination site of synthesized ligand respectively.

\section{Experimental}

General. The carbon and hydrogen content was determined by standard micro-methods in the microanalytical group of the Institute of Chemistry of the Academy of Sciences of Moldova. The copper(II) was determined by trilonometric method using the murexid as indicator [23]. The atomic absorption spectroscopy method at the Automation and Metrology Centre of the Academy of Science of Moldova was used to determine the Ln(III) and 
copper(II) content simultaneously. IR spectra of polycrystalline samples were recorded (4000- $\left.400 \mathrm{~cm}^{-1}\right)$ as oil mulls on a Specord M-75 spectrophotometer. TG studies were performed on a Paulik-Paulik-Erdey derivatograph in air, with platinum crucible, $\mathrm{Al}_{2} \mathrm{O}_{3}$ as calibration standard and at a speed of heating equal to $5{ }^{\circ} \mathrm{C} / \mathrm{min}$. DTG - $1 / 5$; DTA - 1/10; TG - 100/100. $\mathrm{T}_{\max }=1000{ }^{\circ} \mathrm{C}$. Magnetic measurements of II, III, V at $300 \mathrm{~K}$ were performed using Guy method. Variable temperature susceptibility of III was measured with an Oxford Instruments Vibrating Sample Magnetometer (VSM) working between 0 and $12 \mathrm{~T}$ and in the 1.5-350.0 K temperature range.The diamagnetic Pascal's constants were used to correct the magnetic values [2]. To determine the value of $\mu_{\text {eff }}$ the relation $\left(\mu_{\mathrm{eff}}\right)_{\mathrm{M}}=\sqrt{8 \chi_{M} T}$ (B.M.) was used.

Synthesis. All manipulations were performed under aerobic conditions with the initial substances commercially obtained and used without any further purification.

The synthesis of Schiff base $\left(\mathrm{H}_{4} \mathrm{~L}\right)$ was carried out by the addition of ethylene diamine to methanol solution of 2-hydroxy-3-carboxynapthaldehyde in a molar ratio of 1:2. 2-hydroxy-3-carboxynaphtaldehyde was synthesized according to [18]. A precipitate of the ligand, separated on the glass filter, was washed out consequently by alcohol and ether and dried above an anhydrous calcium chloride up to a constant mass. M. p. of a new synthesized ligand, N,N'bis(2-hydroxy-3-carboxynaphtalidene)ethylenediamine is $\sim 310{ }^{\circ} \mathrm{C}$. Found, \%: C, 67.52; H, 4.22; N, 5.85. Calc. for $\mathrm{C}_{26} \mathrm{H}_{20} \mathrm{~N}_{2} \mathrm{O}_{6}, \%$ : C, 68.43; H, 4.38; N, 6.14. The basic IR frequencies, (nujol oil, $\mathrm{cm}^{-1}$ ): 3340mb, 1707s, $1653 \mathrm{~m}, 1627 \mathrm{~s}$, $1613 \mathrm{~s}, 1587 \mathrm{~m}, 1547 \mathrm{~m}, 1533 \mathrm{~m}, 1413 \mathrm{~m}, 1200 \mathrm{ssh}, 1027 \mathrm{~m}, 853 \mathrm{~m}, 800 \mathrm{~m}, 741 \mathrm{~m}, 640 \mathrm{~m}, 480 \mathrm{~m}$.

$\mathrm{Cu}\left(\mathrm{H}_{2} \mathrm{~L}\right)(\mathbf{I I}) \cdot \mathrm{CuCl}_{2} \cdot 2 \mathrm{H}_{2} \mathrm{O}(0.17 \mathrm{~g}, 1 \mathrm{mmol})$ was dissolved in $10 \mathrm{ml}$ of ethanol and added to a suspension of $\mathrm{H}_{4} \mathrm{~L}$ ligand $(0.45 \mathrm{~g}, 1 \mathrm{mmol})$ in $20 \mathrm{ml}$ of ethanol. The solution was heated on the water bath $\left(\sim 70{ }^{\circ} \mathrm{C}\right)$ with permanent stirring on the magnetic stirrer till the green homogeneous precipitate was formed. A final product was filtered off on the glass filter, washed by ethanol and ether and dried above anhydrous $\mathrm{CaCl}_{2}$ up to a constant mass. The yield was $0.32 \mathrm{~g}$ (61\%). Found, \% C, 60.37; H, 4.20; N, 5.78; Cu, 12.10. Calc. for $\mathrm{C}_{26} \mathrm{H}_{18} \mathrm{~N}_{2} \mathrm{O}_{6} \mathrm{Cu}, \%$ : C, 60.30; H, 3.47; N, 5.41; Cu, 12.27. IR spectrum (nujol oil, $\mathrm{cm}^{-1}$ ): $1707 \mathrm{~s}, 1640 \mathrm{~m}, 1627 \mathrm{~s}, 1616 \mathrm{~s}, 1587 \mathrm{~m}, 1547 \mathrm{~m}, 1507 \mathrm{~m}, 1413 \mathrm{~s}, 1200 \mathrm{~m}, 1160 \mathrm{~m}$, $1093 \mathrm{w}, 1027 \mathrm{w}, 853 \mathrm{w}, 800 \mathrm{~m}, 733 \mathrm{~m}, 653 \mathrm{w}, 602 \mathrm{w}, 533 \mathrm{vw}, 467 \mathrm{w}$.

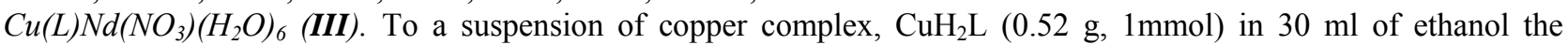
alcohol solution of $\mathrm{LiOH} \cdot \mathrm{H}_{2} \mathrm{O}(2,5 \mathrm{mmol})$ was slowly added. The obtained intermediate complex was separated on the filter, washed out and was further added to $(0.44 \mathrm{~g}, 1 \mathrm{mmol})$ of neodymium nitrate in $10 \mathrm{ml}$ of EtOH. The reaction product of light green color was filtered off, washed out by several portions of alcohol and ether. Yield: $0.43 \mathrm{~g}(56 \%$ relative to). Found, \%: C, 38.18; H, 3.05; N, 4.54; Cu, 8.00; Nd, 18.00. Calc. for $\left(\mathrm{C}_{26} \mathrm{H}_{28} \mathrm{~N}_{3} \mathrm{O}_{15} \mathrm{CuNd}\right), \%: \mathrm{C}, 37.62 ; \mathrm{H}$, 3.37; N, 5.06; Cu, 7.65; Nd, 17.38. IR-spectrum (nujol oil, $\mathrm{cm}^{-1}$ ): 3620mb, 3413mb, 1640m, 1627s, 1600s, $1547 \mathrm{~m}$, $1507 \mathrm{~m}, 1400 \mathrm{~s}, 1308 \mathrm{~m}, 1200 \mathrm{msh}, 1160 \mathrm{w}, 1100 \mathrm{w}, 1030 \mathrm{w}, 880 \mathrm{w}, 800 \mathrm{~m}, 747 \mathrm{~m}, 653 \mathrm{w}, 613 \mathrm{w}, 587 \mathrm{w}, 533 \mathrm{w}, 453 \mathrm{w}$.

$\mathrm{Cu}(\mathrm{L}) \mathrm{Eu}\left(\mathrm{NO}_{3}\right)\left(\mathrm{H}_{2} \mathrm{O}\right)_{4}(\mathbf{I V})$ was synthesized following the similar procedure by the interaction of $\mathrm{CuH}_{2} \mathrm{~L}(0.52 \mathrm{~g}$, $1 \mathrm{mmol})$ with $\mathrm{Eu}\left(\mathrm{NO}_{3}\right)_{3} \cdot 6 \mathrm{H}_{2} \mathrm{O}(1 \mathrm{mmol})$ in the presence of LiOH. Yield: $0.46 \mathrm{~g}(58 \%)$. Found, \%: C, 38.45; H, 3.57; N, 3.68; $\mathrm{Cu}, \sim 9.17 ; \mathrm{Eu}, \sim 14-18$. Calc. for $\left(\mathrm{C}_{26} \mathrm{H}_{24} \mathrm{~N}_{3} \mathrm{O}_{13} \mathrm{CuEu}\right), \%$ : C, 38.94; H, 2.99; N, 5.24; Cu, 7.92; Eu, 18.95. IRspectrum (nujol oil $\mathrm{cm}^{-1}$ ): $3626 \mathrm{mb}, 3386 \mathrm{mb}, 1650 \mathrm{~m}, 1627 \mathrm{~s}, 1600 \mathrm{~m}, 1547 \mathrm{~s}, 1507 \mathrm{~m}, 1400 \mathrm{~s}, 1312 \mathrm{~m}, 1200 \mathrm{~m}, 1160 \mathrm{w}$, $1107 \mathrm{w}, 1027 \mathrm{w}, 880 \mathrm{w}, 800 \mathrm{~m}, 747 \mathrm{~m}, 653 \mathrm{w}, 619 \mathrm{w}, 587 \mathrm{w}, 534 \mathrm{w}, 453 \mathrm{w}$.

$\mathrm{Cu}(\mathrm{L}) \mathrm{Gd}\left(\mathrm{NO}_{3}\right)\left(\mathrm{H}_{2} \mathrm{O}\right)_{6}(\mathrm{~V})$ was synthesized following the similar procedure applying $\mathrm{Gd}\left(\mathrm{NO}_{3}\right)_{3} 6 \mathrm{H}_{2} \mathrm{O}$ as a lanthanide salt $(1 \mathrm{mmol})$. Yield: $0.44 \mathrm{~g}(\sim 52 \%)$. Found, \%: C, 36.65; H, 3.22; N, 5.33; Cu, 8.17; Gd, 14-18. Calc. for $\left(\mathrm{C}_{26} \mathrm{H}_{28} \mathrm{~N}_{3} \mathrm{O}_{15} \mathrm{CuGd}\right.$ ), \%: C, 37.04; H, 3.32; N, 4.98; Cu, 7.53; Gd, 18.65. IR-spectrum (nujol oil, $\left.\mathrm{cm}^{-1}\right): 3600 \mathrm{mb}$, $3410 \mathrm{mb}, 1650 \mathrm{~m}, 1627 \mathrm{~s}, 1600 \mathrm{~s}, 1547 \mathrm{~m}, 1507 \mathrm{~m}, 1400 \mathrm{~m}, 1308 \mathrm{~m}, 1200 \mathrm{~m}, 1160 \mathrm{w}, 1105 \mathrm{w}, 1027 \mathrm{w}, 880 \mathrm{w}, 800 \mathrm{~m}, 747 \mathrm{~m}$, $654 \mathrm{w}, 613 \mathrm{w}, 587 \mathrm{w}, 533 \mathrm{w}, 453 \mathrm{w}$.

The synthesized heteronuclear complexes of the composition $\left\{\mathrm{Cu}(\mathrm{L}) \mathrm{Ln}\left(\mathrm{NO}_{3}\right)\left(\mathrm{H}_{2} \mathrm{O}\right)_{\mathrm{n}}\right\}$ (III-V) are of light green color, stable in air, soluble in dimethylformamide and in dimethylsulfoxide, insoluble in water and in majority of the widespread used organic solvents. Because of weak solubility it was not possible to receive monocrystals for an confirmation of final structure of complexes.

\section{Conclusions}

The interaction of a new ligand (N,N'-bis (2-hydroxy-3-carboxynaphtalidene(ethilenediamine) $\left(\mathrm{H}_{4} \mathrm{~L}\right)$ with the $\mathrm{Cu}^{2+}$ ions results the compound $\mathrm{CuH}_{2} \mathrm{~L}$. The copper(2+) ions coordinate to an interior chromophore $\left(\mathrm{N}_{2} \mathrm{O}_{2}\right)$ of synthesized ligand, the carboxylic groups remaining free. The presence of free carboxylic groups in the $\mathrm{CuH}_{2} \mathrm{~L}$ compound affords a possibility of its use in reaction with salts of homo- and heterometals. The heterocomplexes with composition $\left[\mathrm{CuLn}(\mathrm{L})\left(\mathrm{NO}_{3}\right)\left(\mathrm{H}_{2} \mathrm{O}\right)_{\mathrm{n}}\right]$ were synthesized. Coordination of lanthanide ion $\left(\mathrm{Nd}^{3+}, \mathrm{Eu}^{3+}, \mathrm{Gd}^{3+}\right)$ is supposed to an carboxylate oxygen atoms of ligand. In heterocomplexes the antiferomagnetic exchange for pair $\mathrm{Cu}-\mathrm{Nd}$ is present.

\section{Acknowledgments}

The research described in this publication was made possible in part by the financial support of the INTAS project $n^{\circ}$ 00-00565. The authors are very grateful prof. A.Caneschi for assistance at magnetic investigations of complexes at low temperature and prof. K.Turta for permanent interest and support of these investigations.

\section{References}

[1] Kahn O., Adv. Inorg.Chem., 1995, 43, 179.

[2] Kahn O., Molecular magnetism, VCH Verlagsgesellscaft, Weinheim, 1993. 
[3] Magneto-Structural Correlations in Exchange Coupled Systems, eds. R.D.Willett, D.Gatteschi and O. Kahn, Kluwer Academic Publishers, Dordrecht, 1985.

[4] Magnetic Molecular Materials, eds. D.Gatteschi, O.Kahn, J.S.Miller and F. Palacio, Kluwer Academic Publishers, Dordrecht, 1991.

[5] Mehta B.H., Desai Yogita, Orient. J. Chem. , (1999), 15, 1, 139.

[6] Murray K.S., Adv.Inorg.Chem., 1995, 43, 261.

[7] Research Frontiers in Magnetochemistry, ed. C.J. O'Connor, World Scientific, Singapore, 1993.

[8] Sinn E., Coord.Rev., 1970, 5, 313.

[9] Benelli C. and Gatteschi D., Chem.Rev., (2002), 102, 2369.

[10] Costes J.-P., Dahan F. and Dupuis A., Inorg.Chem., (2000), 39, 169.

[11] Okawa H., Furutachi H . and Fenton D.E., Coord.Chem.Rev., (1998), 174, 51.

[12] Piguet C., Edder C., Rigaut S., et all , J.Chem.Soc., Dalton Trans., (2000), 3999.

[13] Piguet C. and Bunzli J.-C.G., Chem.Soc.Rev., (1999), 28, 347.

[14] Research Frontiers in Magnetochemistry, ed. C.J. O'Connor, World Scientific, Singapore, 1993.

[15] Rudra I., Raghu C. and Ramasesha S., Phys.Rev. B, (2002), 65, 22, 4411.

[16] Sakamoto M., Manseki K. and Okawa H., Coord.Chem.Rev., (2001), 219-221, 379.

[17] Sakamoto M, Takagi M., Ishimori T., Okawa H., Bull.Chem.Soc.Jpn., 1988, 61., 1613.

[18] Brevet of USSR Nr. 37306, (1974), Bull. Nr.27. P. 28.

[19] Shen Hao-Yu, Liang Shu-Yong, Synth. React. Inorg.Met.-Org.Chem., (1998), 28, 6, 907.

[20] Zahra Afrasiabi Ekk Sinn, Prasad P. Kulkarni et all. Inorg. Chim. Acta, (2005), 358, 6, 2023.

[21] Dilip Kumar Saha, Subhash Spadhye, Anson Ch.E. and Powell A.K., Trans.Metal Chem., (2003), $28,579$.

[22] Nakamoto K. Infrakrasnye spectry I spectry KR neorganiceskih I organiceskih soedinenii. Moskva: Mir. -1991, 540p. (rus).

[23] Schwarzenbach G., Flaschka H. Kompleksonometriceskoe titrovanie. Publ. "Himia", Moskva, 1970, 359p. (rus.) 